\title{
FARKLI BUJİ SAYILARI VE KONUMULARINA SAHİP BUJİ ATEŞLEMELI BİR MOTORDA ATEŞLEME AVANSININ MOTOR PERFORMANS PARAMETRELERİ ÜZERÍNDEKİ ETKİSİ
}

\author{
İsmail ALTIN ${ }^{1}$, Atilla BíLGíN ${ }^{2}$ \\ ${ }^{1}$ Karadeniz Teknik Üniversitesi, Sürmene Deniz Bilimleri Fakültesi, Gemi İnşaatı ve Gemi Makineleri \\ Mühendisliği Bölümü, 61530, Trabzon \\ ${ }^{2}$ Karadeniz Teknik Üniversitesi, Mühendislik Fakültesi, Makina Mühendisliği Bölümü, 61080, Trabzon \\ isaltin@ktu.edu.tr; $\underline{\text { bilgin@ } @ \text { ktu.edu.tr }}$
}

(Geliş/Received: 29.05.2014; Kabul/Accepted: 05.04.2016)

ÖZET

\begin{abstract}
$\mathrm{Bu}$ çalışmanın amacı, çift bujili buji ateşlemeli (BA) bir motorda ateşleme avansının motor performans parametreleri üzerindeki etkisini incelemektir. Çalışmada sanki-boyutlu termodinamik çevrim modeli kullanılmıştır. Simülasyondaki alev yayılması süreci katı model programı kullanılarak modellenmiş̧tir. Ateşleme avansı başta olmak üzere, ekivalans oranı $(\phi)$ ve bujilerin silindir kafasındaki üç farklı konumu çalışmanın inceleme parametrelerini oluşturmaktadır. Elde edilen sonuçlardan, merkezde tek bujiye sahip geometrinin genellikle en iyi motor performans karakteristiklerine sahip olduğu, simetrik çift buji kullanılmasının yanmayı hızlandırması sonucu merkezde tek bujili geometrinin karakteristiklerine yakın değerler verdiği belirlenmiştir. Kenarda tek buji olarak adlandırılan geometri ise buji konumundan dolayı alev yolunun uzaması sonucu en kötü motor performans karakteristikleri vermiştir.
\end{abstract}

Anahtar Kelimler: Çift bujili buji ateşlemeli motor, sanki-boyutlu termodinamik çevrim modeli, motor performansı, ateşleme avansı

\section{THE EFFECT OF SPARK ADVANCE ON ENGINE PERFORMANCE CHARACTERISTICS IN A SPARK IGNITION ENGINE HAVING VARIOUS SPARK PLUG NUMBERS AND LOCATIONS}

\begin{abstract}
The aim of this study is to investigate the effect of spark advance on engine performance parameters in a twin spark SI engine. Quasi-dimensional thermodynamic engine cycle model has been used in the study. Flame propagation process in the simulation has been modeled by solid model software. Equivalence ratio $(\phi)$, three various locations of the spark plug(s) on cylinder head, and mainly spark advance has been operating parameters of the study. It has been determined that the geometry having centrally located spark plug(s) gives the best combustion and performance characteristics from the results of the study. Using of twin spark plugs gives closer combustion and performance characteristics due to increasing combustion speed. The mid-radius located single spark geometry gives the worst characteristics since it has the longest flame travelling length.
\end{abstract}

Keywords: Twin spark SI engine, quasi-dimensional thermodynamic cycle model, engine performance, spark advance

\section{GİRIŞ (INTRODUCTION)}

BA motorlarda yüksek performans ve düşük değerlerde kirletici emisyonlarının elde edilebilmesi için, tekrarlanabilir ve güvenilir bir ateşleme işleminin en uygun zamanda gerçekleştirilmesi gerekmektedir
[1-3]. Bu olgu, BA motorlarda ateşleme avansının önemli bir fonksiyonel etkiye sahip olduğunu göstermektedir [4]. Bu bağlamda, ateşleme avansı maksimum silindir basıncının oluşacağı krank mili açısının belirleyici bir öğesidir [5] ve BA motorlarda yanma işleminin ana kontrol parametresini 
oluşturmaktadır [3]. Taze dolgunun bileşimi, sıkıştırma oranı, motor devir sayısı, türbülans, gaz kelebeğinin pozisyonu, batarya gerilimi, hava/yakıt oranı, havanın nemliliği, hava sıcaklığı, EGR, soğutucu sicaklığı, motor yükü ve yakıtın tipi optimum ateşleme avansının belirlenmesinde önemli bir rol oynamaktadır [6-9]. Ateşleme avansını etkileyen tüm parametrelerin ölçülmesi hem pahalıdır hem de pratik değildir. $\mathrm{Bu}$ nedenle ateşleme avansı için pik basınç yöntemi, kütlesel yanma oranı yöntemi ve basınç oranı yöntemi olarak isimlendirilen bazı deneysel yaklaşımlar kullanılmaktadır [5]. Ayrıca, ateşleme avansı belirlenirken; en yüksek döndürme momentinin elde edilmesi, yakıt tüketiminin, emisyonların ve vuruntunun azaltılması kriterleri de göz önünde bulundurulmalıdır [6]. Böylece, yapılan incelemeler sonucunda ilgili BA motor için en genel kullanım şekliyle; devir sayısı, motor yükü ve ateşleme zamanlamasından oluşan ateşleme haritası elde edilmektedir. Haritadaki ateşleme zamanları en yüksek döndürme momentine (MBT) karşılık gelen krank mili açılarını ifade etmektedir. Farklı BA motorlar için ateşleme haritalarının özel olarak elde edilmesi gerekmektedir [6, 10-11]. BA motorlarda etkin ateşleme; başarılı bir yanma işlemi için büyük bir öneme sahiptir. Ateşleme işlemi; ark enerjisi, pik voltaj, deşarj süresi, buji tırnak boşluğu ve bujinin yanma odasında sıkıştırılmış dolgunun geometrisine göre konumu gibi çok sayıda değişkene bağlıdır [12]. Düşük yakıt tüketimi beklentisi ve egzoz emisyon sınırlamaları nedeni ile BA motorların fakir karışımla $(\phi<0,7)$ çalıştırılması zorunluluğu ortaya çıkmaktadır. BA motorlarda, güvenilir ve başarılı bir ateşleme işlemini garanti etmek için; yüksek enerji ile çalışan bujiler, lazer tekniği, mikrodalga tekniği, silindir kafasında çift buji kullanımı tekniği vb. çok çeşitli ateşleme teknikleri geliştirilmiştir $[12,13]$. Bu uygulamalardan, yüksek ateşleme enerjisi ve çift buji ile ateşleme yöntemlerinin önemli üstünlükleri nedeniyle öne çıktıkları görülmektedir [1, 13]. Bu çalışmanın odağında BA motorlarda çift buji ile ateşleme yönteminin kullanımı bulunmaktadır. Çift buji ile ateşleme yönteminde; silindir kafasında eksenel simetrik [13, 14] veya diyagonal [15] olarak yerleştirilmiş iki adet buji yer almaktadır. Bujilerde ateşleme işlemi çalışma koşullarına bağlı olarak eş zamanlı veya siralı olarak yapilabilmektedir [16]. Dolgu kalitesi ateşleme sistemi ile önemli bir etkileşime sahiptir [17]. Düşük yakıt/hava oranlarına ve yüksek EGR oranlarına sahip karışımlar ile BA motorun düşük yükte çalışması ateşleme işlemini zorlaştıran koşulları oluşturmaktadır [17, 18]. Tek buji kullanılan sistemlerde, buji tırnakları arasında bu zor koşullar altında tutuşabilecek kadar bir yakıt/hava karışımının bulunmaması durumunda ilgili çevrimde yanma işlemi büyük olasılıkla gerçekleşemeyecektir. Silindir kafasında çift buji kullanılması, taze dolgunun tutuşamama riskini artan ateşleme noktası sayesinde istatistiksel olarak azaltmakta ve yanma işleminin başlatılmasını yüksek oranda garanti etmektedir [4].
Çift buji yanmanın bu ilk aşamasında sağladığı iyileştirmeden dolayı BA motorda kararlı bir çalışmayı da sağlamış olmaktadır. Bu durum hızlı yanma oranı ile doğrudan ilişkilidir [17]. BA motorda çift buji kullanılmasının sağlamış olduğu diğer avantajlar da şu şekilde özetlenebilir [19-27]:

Alev yolunun kısalması ile birlikte yanma süreleri de belirgin şekilde kısalmaktadır. Kullanılan yakıta bağlı olarak daha yüksek sıkıştırma oranlarında çalışma olanağı ortaya çıkmaktadır. İki noktadan yapılan ateşleme işlemi tutuşma gecikmesinin azalmasını sağlamaktadır. Yanmayı iyileştirmek için silindir içinde ek hava hareketlerine olan gereksinimi azaltmaktadır ve böylece 1sı kayıplarının azalması sonucunda da özgül yakıt tüketiminde azalma elde edilmektedir. Elde edilen hızlı yanma vuruntu direncinin artmasını sağlamaktadır. Çevrimden çevrime olan farklılık azalmaktadır. Optimum ateşleme zamanının (MBT) ÜÖN'ya yaklaşmasını sağlanmaktadır. $\mathrm{Bu}$ da, gerçek çevrimin Otto çevrimine daha fazla yaklaşmasını ve termik verimin artmasını sağlamaktadır.

Literatürde; tek bujili ateşleme sistemine sahip BA motorlar için ateşleme avansının/zamanının yanma karakteristikleri ve motor performans parametreleri üzerindeki etkilerini inceleyen çok sayıda çalışma bulunmaktadır [28, 29]. Buna karşın, çift bujili BA motorda ateşleme avansının motor performans parametreleri üzerindeki etkisinin ayrıntılı olarak incelendiği bir çalışmaya rastlanmamıştır. Bozza vd. [16] iki farklı ateşleme avansı, sabit devir sayısı ve kısmi yük durumu için BA motorun yakıt tüketimlerini tek ve iki noktadan ateşleme yapılması koşulları altında karşılaştırmışlardır. Özgül yakıt tüketimi, BA motorda çift bujinin (iki noktadan ateşlemenin) kullanıldığı durumda daha düşük değerler almıştır. Lavergne ve Hallot [23] tek ve çift buji kullanılabilen BA motorda kısmi yükte farklı EGR konsantrasyonları ve ateşleme zamanları için yanma süreçlerini üç boyutlu benzetim tekniğini kullanarak incelemişlerdir. Çalışmalarının sonucunda çift buji ile ateşleme işlemi yapılması durumunda en yüksek indike ortalama basınç değerinin elde edildiğini belirlemişlerdir. Fieronza vd. [25] çift bujili küçük bir benzin motorunda gürülttü emisyonunu kısmi ve tam yükte deneysel olarak incelemişlerdir. Çift bujili ateşleme sisteminde uygun seçilen ateşleme avanslarının yanma gürültüsünün azalmasına katkı sağladığını belirlemişlerdir. Yapılan kaynak araştırmasında; çift bujili BA motorlarda ateşleme avansının motor performans parametreleri üzerinde etkisinin çok kısıtlı olarak ele alındı ğı belirlenmiştir. $\mathrm{Bu}$ çalışmada; buji sayısı (tek ve çift), üç farklı buji konumu ve üç farklı ekivalans oranı çalışma parametresi olarak ele alınmıştır. $\mathrm{Bu}$ çalışma parametreleri dikkate alınarak, ateşleme avansının motor performans parametreleri üzerindeki etkisi buji konumuna göre karşılaştırmalı olarak gerçek bir çift bujili BA motor için incelenmiştir. 


\section{TEORIK MODEL (THEORETICAL MODEL)}

\subsection{Termodinamik Model (Thermodynamic Model)}

BA bir motor için termodinamik çevrim modeli; esas olarak termodinamiğin birinci yasasına dayanmaktadır. Birinci yasanın krank mili açısına (zamana) göre diferansiyelinin alınması ile aşağıdaki denklem elde edilir [30].

$m \frac{d u}{d \theta}+u \frac{d m}{d \theta}=\frac{d Q}{d \theta}-p \frac{d V}{d \theta}-\frac{\dot{m}_{L} h_{L}}{\omega}$

Sanki-boyutlu termodinamik esaslı modellerde yanma odası, küresel olarak yayıldığı kabul edilen alev cephesi tarafindan yanmış ve yanmamış bölgelere ayrılır (Şekil 1).

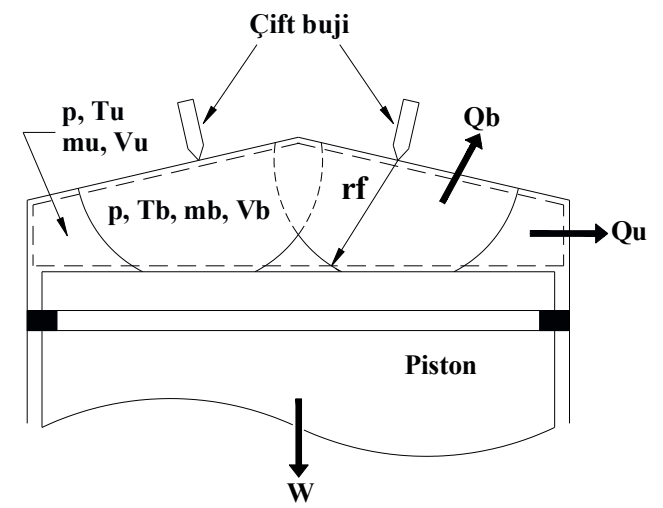

Şekil 1. İki bölgeli yanma modeli (Two zone combustion model)

Her bir bölgeye termodinamiğin birinci yasası, ideal gaz denklemi, kütlenin korunumu ve yanmış $(b)$ ve yanmamış $(u)$ bölge hacimlerinin toplamının korunumu denklemleri uygulanarak uygun düzenlemeler yapıldığında; basınç $(p)$, yanmış ve yanmamış gaz bölgeleri sıcaklıkları $(T)$, indike iş $(W)$, 1S1 kaybı $\left(Q_{L}\right)$ ve entalpi kaybı $\left(H_{L}\right)$ için 2-7 denklemleri ile verilen 1 . mertebeden adi diferansiyel denklem sistemi elde edilir. Burada yanma odas1 boyunca (yanmış ve yanmamış gaz bölgelerinde) basıncın aynı olduğu kabul edilmektedir. Elde edilen diferansiyel denklem sisteminin eş zamanlı olarak çözülmesi ile elde edilen indike iş ve mekanik kayıplar için kullanılan deneysel bağıntılardan yararlanılarak, efektif büyüklükler hesaplanmaktadır.

$\frac{d p}{d \theta}=\frac{A+B+C I}{D+E}$

$$
\begin{aligned}
\frac{d T_{b}}{d \theta}= & -\frac{h_{g b} A_{b}\left(T_{b}-T_{w}\right)}{\omega m C_{p_{b}} x_{b}}+\frac{v_{b}}{C_{p_{b}}} \frac{\partial \ln v_{b}}{\partial \ln T_{b}} \frac{d p}{d \theta} \\
& +\frac{h_{u}-h_{b}}{x_{b} C_{p_{b}}}\left[\frac{d x_{b}}{d \theta}-\left(x_{b}-x_{b}^{2}\right) \frac{C}{\omega}\right]
\end{aligned}
$$

$\frac{d T_{u}}{d \theta}=-\frac{h_{g u} A_{u}\left(T_{u}-T_{w}\right)}{\omega m C_{p_{u}}\left(1-x_{b}\right)}+\frac{v_{u}}{C_{p_{u}}} \frac{\partial \ln v_{u}}{\partial \ln T_{u}} \frac{d p}{d \theta}$

$\frac{d W}{d \theta}=p \frac{d V}{d \theta}$

$\frac{d Q_{L}}{d \theta}=\left[h_{g b} A_{b}\left(T_{b}-T_{w}\right)+h_{g u} A_{u}\left(T_{u}-T_{w}\right)\right] / \omega$

$\frac{d H_{L}}{d \theta}=\frac{C m}{\omega}\left[\left(1-x_{b}^{2}\right) h_{u}+x_{b}^{2} h_{b}\right]$

Denklem (2)'deki parametreler, 8-13 bağıntıları yardımıyla hesaplanmıştır:

$$
A=\frac{1}{m}\left(\frac{d V}{d \theta}+\frac{V C}{\omega}\right)
$$

$$
\begin{aligned}
B=\frac{1}{\omega m} & {\left[h_{g b} \frac{v_{b}}{C_{p_{b}}} \frac{\partial \ln v_{b}}{\partial \ln T_{b}}\left(1-\frac{T_{w}}{T_{b}}\right) A_{b}\right.} \\
& \left.+h_{g u} \frac{v_{u}}{C_{p_{u}}} \frac{\partial \ln v_{u}}{\partial \ln T_{u}}\left(1-\frac{T_{w}}{T_{u}}\right) A_{u}\right]
\end{aligned}
$$

$$
\begin{aligned}
C I= & -\left(v_{b}-v_{u}\right) \frac{d x_{b}}{d \theta} \\
& -v_{b} \frac{\partial \ln v_{b}}{\partial \ln T_{b}} \frac{h_{b}-h_{u}}{C_{p_{b}} T_{b}}\left[\frac{d x_{b}}{d \theta}-\frac{\left(x_{b}-x_{b}^{2}\right) C}{\omega}\right]
\end{aligned}
$$

$$
D=x_{b}\left[\frac{v_{b}^{2}}{C_{p_{b}} T_{b}}\left(\frac{\partial \ln v_{b}}{\partial \ln T_{b}}\right)^{2}+\frac{v_{b}}{p} \frac{\partial \ln v_{b}}{\partial \ln p}\right]
$$

$$
E=\left(1-x_{b}\right)\left[\frac{v_{u}^{2}}{C_{p_{u}} T_{u}}\left(\frac{\partial \ln v_{u}}{\partial \ln T_{u}}\right)^{2}+\frac{v_{u}}{p} \frac{\partial \ln v_{u}}{\partial \ln p}\right]
$$

$$
\begin{aligned}
V(\theta)= & V_{c}\left\{1+\frac{\varepsilon_{s}-1}{2}[1-\cos (\theta)\right. \\
& \left.\left.+\frac{1}{r_{L}}\left(1-\sqrt{1-\left(r_{L} \sin (\theta)\right)^{2}}\right)\right]\right\} ; r_{L}=\varepsilon_{s} / l_{b}
\end{aligned}
$$

\subsection{Geometrik Model (Geometrical Model)}

BA motorlar için geliştirilen sanki-boyutlu termodinamik çevrim modelindeki çeşitli çevrim parametrelerini hesaplanmasinda alev cephesinin geometrik özellikleri kilit rol oynamaktadır [31-33]. Alev cephesinin geometrik özellikleri kütlesel yanma oranının ve yanma odasindan olan 1S1 kaybının hesaplanmasında kullanılmaktadır. Bu özelliklerin hassas bir şekilde hesaplanması ile teorik modelden 
daha gerçekçi sonuçların elde edilmesi sağlanabilmektedir. $\mathrm{Bu}$ çalışmada, alev cephesinin geometrik özelliklerinin elde edilmesinde SolidWorks katı model programı kullanılmıştır [10]. Bu amaçla, öncelikle yanma odasının katı modeli oluşturulmuştur $[10,34]$. Bu katı modelin hacmi alev yayılmasının henüz başlamadığı (ateşleme öncesi) süreçte tamamen taze dolguyu temsil etmektedir. Ateşleme işleminden sonra alev yayılmasının modellenmesi için buji konumunu/konumlarını merkez alan ve yarıçapı maksimum alev yarıçapı değerine kadar artan küre/küreler kullanılmıştır. Kürenin gerisinde kalan hacim yanmış gazlara karşılık gelmektedir. Şekil 2'de modelleme işlemi bitmiş çift bujili bir BA motorun yanma odası modeli ve belirli bir alev yarıçapı için alevin gerisinde kalan yanmış gazları gösteren durum ifade edilmektedir. Küre ile yanma odasındaki taze dolgu arasındaki ve kürenin silindir duvarı $(w)$ ile olan kesişim yüzey alanları $(A)$ katı model programının hesaplama araçları kullanılarak hesaplanmaktadır. Önceden belirlenen krank açısı ve maksimum alev yarıçapı aralıklarında alev cephesinin geometrik özellikleri bu şekilde belirlenerek tablo haline getirilmektedir. Daha sonra çevrimin hesaplanması için hazırlanan bilgisayar programında gerekli anlarda bu veriler tablolardan alınarak kullanılmaktadır [10, 35]. Şekil 3'te silindir kafasında simetrik çift buji için $\theta=0-90^{\circ} \mathrm{KMA}$ aralığında elde edilen 14397 adet tablo verisinden alev cephesi serbest yüzey alanı için olanları eş alan eğrileri şeklinde örnek olarak verilmiştir. Bu çalışmada kullanılan diğer buji konumları ve alev cephesinin değdiği yanma odası yüzey alanları için de benzer şekilde tablo verileri elde edilmiştir. Çalışmada kullanılan toplam tablo verisi sayısı 53628 adettir. Tablo verileri 1 derece krank mili açısı ve $1 \mathrm{~mm}$ alev yarıçapı artımlarıyla düzenlenmiştir. Ara açı değerleri ve ara alev yarıçapları için alev cephesi geometrik özelliklerin belirlenmesinde bilgisayar programında doğrusal interpolasyon yöntemi kullanılmıştır. Şekil 3'te verilen geometrik özelliklere benzer şekilde, çalışmada 1sı transfer yüzey alanı ve alev cephesi gerisinde kalan yanmış gaz hacimleri için de geometrik veriler elde edilmiştir. $\mathrm{Bu}$ verilerin ayrıntıları Kaynak 10'dan incelenebilir. Çalışmada kullanılan buji sayıları ve konumları Şekil 4'te verilmiştir.

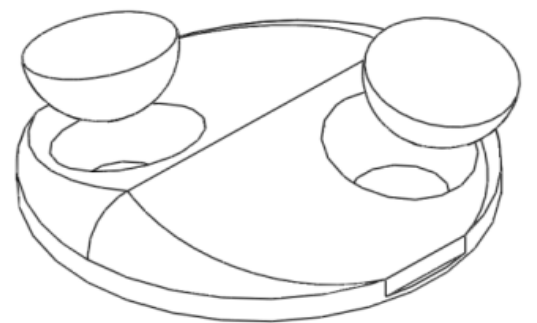

Şekil 2. Çift bujiden alev yayılması durumu için 3D katı model uygulaması (3D solid model application for case of flame propagation from twin spark plugs)

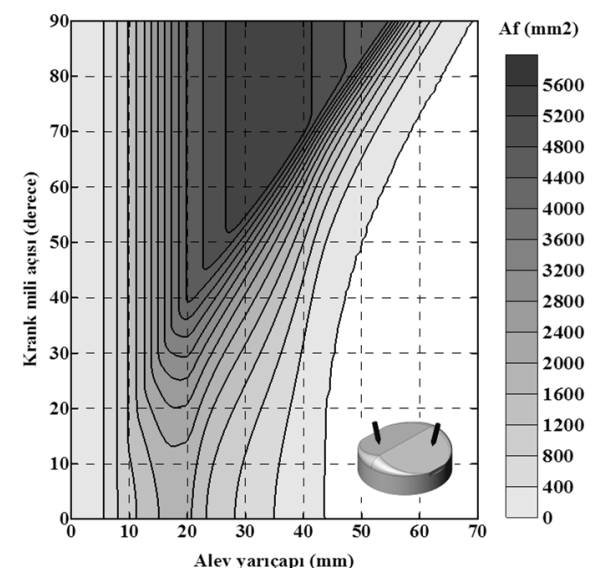

Şekil 3. Çift buji yerleşimi için alev cephesinin serbest yüzey alanının haritası (Free surface area map of flame front for dual-plug arrangement)

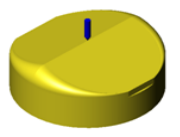

(a)

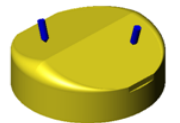

(b)

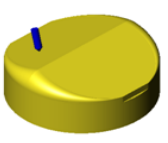

(c)
Şekil 4. Buji sayıları ve konumları (Numbers and locations of spark plug(s))

\subsection{Performans Parametrelerinin Hesaplanması (Computation of the Performance Parameters)}

Çevrim sonunda; efektif verim, efektif güç vb. motor performans parametreleri hesaplanmıştır [36]. Konuya ilişkin ayrıntılı bilgiler ilgili kaynakta [36] veya benzeri temel kaynaklarda $[30,37]$ bulunabilir. Aşağıda, sunulan çalışmada kullanılan başlıca bağıntılar sıralanmıştır (14-20):

Ortalama indike basınç:

$p_{m i}=W_{i} / V_{h}$

Mekanik kayıplar ortalama basıncı:

$p_{m, m}=0.34+0.0113 V_{p m}$

Ortalama efektif basınç:

$p_{m e}=p_{m i}-p_{m, m}$

Efektif verim:

$\eta_{e}=\left(p_{m e} R T_{0}\right) /\left(F_{s} \phi H_{u} p_{0} \eta_{v}\right)$

Özgül yakıt tüketimi:

$b_{e}=3600 / H_{u} \eta_{e}$

Efektif güç:

$P_{e}=p_{m e} V_{h} z n / k / 60 ; k=2$ 
Döndürme momenti:

$$
M_{d}=30 P_{e} / \pi / n
$$

\section{4 Çözüm Yöntemi (Solution Method)}

Sunulan çalışmada, termodinamik model için elde edilen denklem takımı (Denklem 2-7) birince mertebeden adi diferansiyel denklemlerden oluşmaktadır. Bu matematiksel modele dayalı olarak Fortran dilinde bir bilgisayar programı geliştirilmiştir. Motorun geometrik özellikleri, dış ortam ve çalışma koşulları, diferansiyel denklem takımının çözülebilmesi için başlangıç koşulları olarak programa dışarıdan girilmektedir. Programda işlem adımları birer derecelik krank mili açısı adımlarıyla gerçekleştirilmektedir. Sıkıştırma başlangıcı özellikleri olarak emme sonu özellikleri; yanma başlangıcı özellikleri olarak ise sıkıştırma sonu özellikleri dikkate alınmaktadır. Yanma işlemi üst ölü noktadan önce $\theta_{\mathrm{s}}$ ateşleme açısında başlamaktadır. Ateşleme işleminden sonraki ilk krank açısında silindir dolgusunun adyabatik olarak s1kıştırıldı ğ varsayımına dayanarak yanmış gaz sıcaklığı adyabatik alev sıcaklığından hesaplanmıştır. Yanmış kütle için ilk yaklaşım değeri kosinüs yanma denkleminden sağlanmıştır [32]. Programda; sıkıştırma, yanma ve genişleme işlemleri süresince modele ait adi diferansiyel denklem takımının eşzamanlı olarak çözümlenmesinde dördüncü mertebeden klasik Runge-Kutta yöntemi kullanılmıştır. Başlangıç koşulları Tablo 1'de verilmiştir [10, 13, 30, 33, 37]. Ayrıca iş, 1sı kaybı ve entalpi kaybı için çözüm işleminde başlangıç değeri sıfır alınmıştır.

Tablo 1. Bilgisayar programı için giriş verileri (Input data for computer code)

\begin{tabular}{ll}
\hline Program girdisi & Açıklama \\
\hline Çalıșma koşulu & Tam yük \\
Yakıt tipi & Benzin $(\mathrm{C} 7 \mathrm{H} 17)$ \\
Stokiyometrik yakıt/hava oranı & 0.06548 \\
Oktan sayısı & 91 \\
Emme sonu basınç ve sıcaklık & $1 \mathrm{bar}, 350 \mathrm{~K}$ \\
Artık gazlar katsayısı oranı & 0.1 \\
Yanma odası duvar sıcaklığı & $400 \mathrm{~K}$ \\
Hacimsel verim & $\% 85$ \\
\hline
\end{tabular}

\subsection{Teorik Modelin Doğrulanması (Validation of Theoretical Model)}

Teorik modelin doğruluğu Migita vd. [15] tarafindan verilen deneysel sonuçlarla yapılan karşılaştırmalarla gösterilmiştir. Çalışmada kullanılan BA motorun temel özellikleri Tablo 2'de verilmiştir.

Tablo 2. Motor özellikleri [15].(Engine specifications)

\begin{tabular}{ll}
\hline Motorun modeli & Honda L13A \\
\hline Çap $\times$ Strok $(\mathbf{D} \times \mathbf{H})(\mathbf{m m})$ & $73 \times 80$ \\
Biyel kolu uzunluğu $\left(\boldsymbol{l}_{\boldsymbol{b}}\right)(\mathbf{m m})$ & 135 \\
Strok hacmi $\left(\boldsymbol{V}_{\boldsymbol{h}}\right)\left(\mathbf{c m}^{\mathbf{3}}\right)$ & 1339 \\
Sikıştırma oranı $\left(\boldsymbol{\varepsilon}_{\boldsymbol{s}}\right)$ & 10.8 \\
Ateşleme sistemi & İki noktadan \\
$\mathbf{P e}_{\text {maks }}-\mathbf{n}(\mathbf{k W}-\mathbf{d} / \mathbf{d})$ & $63-5700$ \\
$\mathbf{M d}_{\text {maks }} \mathbf{n}(\mathbf{N m}-\mathbf{d} / \mathbf{d})$ & $119-2800$ \\
\hline
\end{tabular}

Karşılaştırma işleminde döndürme momentinin ve efektif gücün devir sayısına göre değişimi esas alınmıştır. Şekil 5 incelendiğinde hesaplanan performans karakteristiklerinin deneysel sonuçlarla uyum içinde olduğu açıkça görülmektedir. Döndürme momentinin ve efektif gücün deneysel ve hesaplama sonucunda elde edilen maksimum değerleri karşılaştırıldığında, sırasıyla yaklaşık \%11,23 ve \%3,84'lük bir farkın ortaya çıktığı görülmektedir. Çift bujili BA motorun çalışması sürecinde bujiler eş zamanlı veya sıralı olarak ateşlenebilmektedir. Sıralı ateşleme düşük devir sayılarında döndürme momentinin bir miktar iyileştirilmesine katkıda bulunmaktadır. Sunulan çalışmada karşılaştırma işleminde kullanılan performans parametreleri sıralı ateşleme durumunda elde edilen deneysel verilere dayanmaktadır. $\mathrm{Bu}$ durum teorik çalışmada elde edilen verilerle deneysel sonuçlar arasında bir miktar farklılıkların ortaya çıkmasına neden olduğu ifade edilebilir. Ayrica, termodinamik modelin oluşturulmasında dikkate alınan varsayımlar [10, 13] ve termodinamik modele yansitılmasinı zor olan; yanma işlemindeki karmaşık kimyasal yapı, silindir içi akışkan hareketleri vb. diğer fiziksel olaylar sunulan çalışma ile deneysel veriler arasındaki farkın ortaya çıkmasına neden olmuştur.

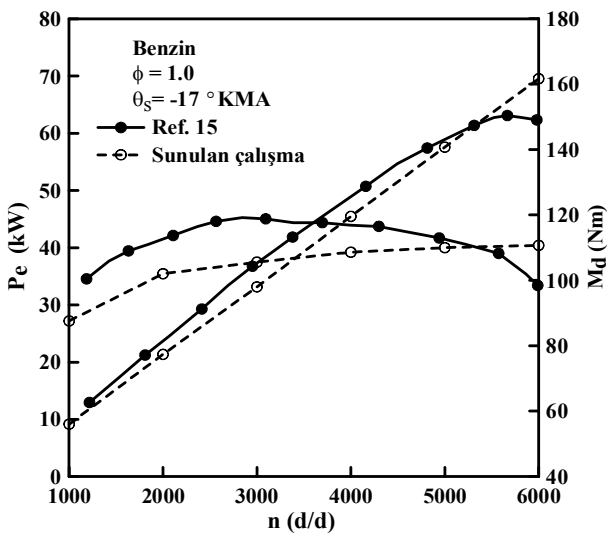

Şekil 5. Teorik modelin geçerliliğinin gösterilmesi (Validation of the theoretical model)

\section{BULGULAR VE TARTIŞMA (RESULTS AND DISCUSSION)}

3.1 Ortalama Efektif Basıncın Ateşleme Avansına Göre Değişimi (Variation of Mean Effective Pressure versus Spark Advance)

Ortalama efektif basınç motorun birim strok hacminde üretilen işin bir göstergesi olup farklı boyutlara sahip motorların karşılaştırılması bakımından önem taşımaktadır. Şekil 6 incelendiğinde; fakir karışım $(\phi=0,8)$ durumunda tüm ateşleme avansı değerleri için merkezde tek buji en yüksek ortalama efektif basınç değerlerini, kenarda tek buji en düşük ortalama efektif basınç değerlerini vermekte olduğu görülmektedir. Simetrik çift buji durumundaki karakteristik merkezde tek bujiye benzer fakat bir miktar daha düşüktür. Yanma hızı yaklaşık $\phi=1,1$ değeri civarında en yüksek değerini 
almaktadır. $\phi=1,0$ ve $\phi=1,2$ ekivalans oranlarında yanma hızları birbirine çok yakın değerler almaktadır [30]. Bu nedenle $\phi=1,0$ ve $\phi=1,2$ durumları için belirgin bir fark ortaya çıkmamaktadır. Ancak $\phi=0,8$ olması durumunda yanma hızları oldukça düştüğünden kenarda tek buji durumu için maksimum silindir basıncı genişleme stroğunun ileri aşamalarına ötelenmektedir. $\mathrm{Bu}$ da ortalama efektif basınç değerlerinin düşmesine ve kenarda tek buji konumu için belirgin bir farkın doğmasına neden olmuştur. Merkezde tek buji ve simetrik çift buji durumlarında yanma işleminin yeterince hızlı olması ateşleme avansının ÜÖN'ya yaklaşması ile birlikte ortalama efektif basıncın artmasını sağlamıştır.

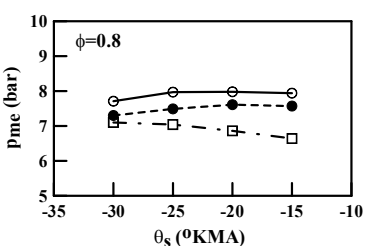

(a)

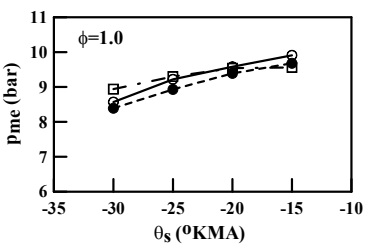

(b)

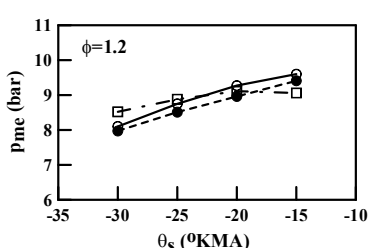

(c)

Şekil 6. Ortalama efektif basıncın farklı buji konumları için ateşleme avansına göre değişimi (Variation of mean effective pressure versus spark advance for various plug locations)

\subsection{Efektif Gücün Ateşleme Avansına Göre} Değişimi (Variation of Break Power versus Engine Speed)

Şekil 7'de efektif gücün AA'ya göre değişimleri verilmektedir. Ortalama efektif basınç değerinin etkisi güçteki değişime çok benzer bir yapıdadır. Ortalama efektif basıncın değişimi için yapılan yorumlar efektif güç için de geçerlidir. Yüksek AA değerlerinde KTB durumunda efektif güçte meydana gelen düşüş, MTB ve SÇB'de oluşmamaktadır.
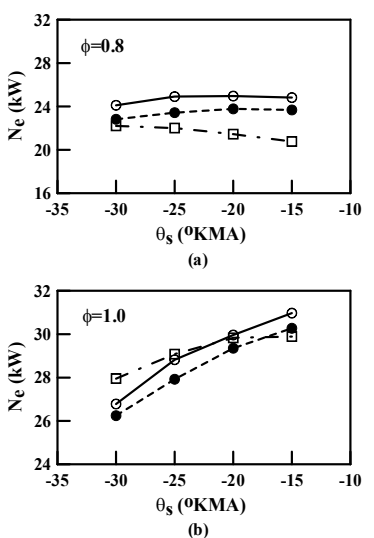

Şekil 7. Efektif gücün farklı buji konumları için ateşleme avansına göre değişimi (Variation of effective power versus spark advance for various plug locations)
3.2 Özgül Yakıt Tüketiminin Ateşleme Avansına Göre Değișimi (Variation of Engine Break Specific Fuel Consumption versus Spark Advance)

Özgül yakıt tüketimi (ÖYT), özellikle farklı boyutlara (büyüklüklere) sahip motorların ekonomikliklerinin karşılaştırılması açısından büyük önem taşımaktadır. Ortalama efektif basınç ve güçteki değişim ÖYT'de kendini belirgin bir şekilde göstermektedir. Bölüm 3.1'de ifade edilen gerekçeler yanma işleminin niteliğini önemli ölçüde etkilemektedir. Yanma işleminin optimum değerlere yakın gerçekleşmesi motordan daha fazla güç üretilmesini sağlamaktadır. Motordan elde edilen gücün artması ile birlikte ÖYT'deki düşüş beklenen doğal bir sonuçtur. Şekil 8'de özgül yakıt tüketiminin AA'ya göre değişimi verilmektedir. Şekiller incelendiğinde, MTB ve SÇB durumlarında hızlı yanma nedeniyle çevrimin Otto çevrimine benzemesi, özellikle düşük AA değerlerinde ÖYT'nin düşmesini sağlamaktadır. Fakir karıșım durumunda $(\phi=0,8)$ AA'nın $-15^{\circ} \mathrm{KMA}$ için, ÖYT'nin değeri MTB'ye göre, SÇB'de $\% 4,5$ ve KTB'de \%19,5 fazla olmaktadır. MTB durumunda AA'nın -30'dan -15 ${ }^{\circ} \mathrm{KMA}$ 'ya düşürülmesi özgül yakıt tüketiminin değerinde yaklaşık \%3'lük bir azalmanın gerçekleşmesini sağlamaktadır.
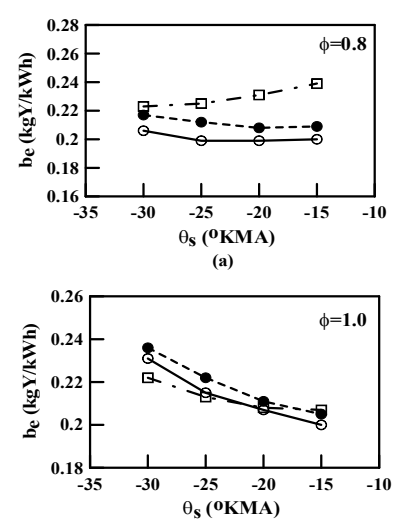

(b)

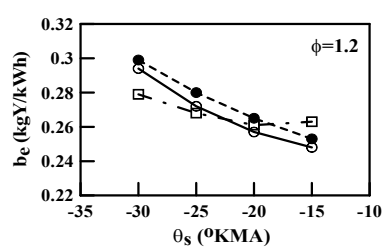

Şekil 8. Özgül yakıt tüketiminin farklı buji konumları için ateşleme avansına göre değişimi (Variation of specific fuel consumption versus spark advance for various plug locations)

\section{SONUÇLAR (CONCLUSIONS)}

$\mathrm{Bu}$ çalışmada; çift bujili bir BA motorda ateşleme avansının motor performans parametreleri üzerindeki etkisi incelenmiştir. Çalışmadan çıkarılabilecek sonuçlar aşağıda sıralanmıştır: BA motorun fakir karışımla çalışma koşulu $(\phi=0.8)$ için çift bujinin kullanılması durumunda; incelenen ateşleme avansı aralığı dikkate alındığında, BA motorda optimum duruma yakın (MTB) performans değerlerinin elde edildiği belirlenmiştir. En kötü performans değerleri BA motorda silindir kafasında KTB kullanılması durumunda elde edilmiştir. Özellikle, azalan ateşleme avansı ile birlikte özgül yakıt tüketimi değerinin hızla kötüleşmeye gittiği görülmüştür. MTB ve SÇB durumlarında ateşleme avansı ÜÖN'ya yaklaştıkça, elde edilen motor performans değerleri birbirlerine yaklaşmıştır. Bunun nedeni MTB ve SÇB 
durumlarında meydana gelen hızlı yanma ve AA düşük seçilmesinin çevrimi yapı olarak Otto çevrimine yaklaştırmış olmasıdır. BA motorlarda bujinin silindir kafasında olabildiğince merkezi konuma yerleştirilmesi optimum performans değerlerinin elde edilmesini sağlamaktadır. Motorların gelişimine bağlı olarak silindir kafasında bujinin merkezi olarak yerleştirilmesini zorlaştıran (artan supap sayısı, yakıt enjektörü vb.) çeşitli teknik gerekçeler ortaya çıkmaktadır [13]. $\mathrm{Bu}$ gibi durumlarda BA motorlarda silindir kafasında simetrik çift buji kullanımı çalışma koşullarının optimum değerlere yaklaştırılmasında büyük rol oynayacağ sunulan çalışmada gösterilmiştir.

\section{SEMBOLLER VE KISALTMALAR (SYMBOLS AND ABBREVIATIONS)}

A : Isı transferinin gerçekleştiği toplam yüzey alanı $\left[\mathrm{m}^{2}\right]$

AA : Ateşleme avansi $\left[{ }^{\circ}\right]$

$b_{e} \quad$ : Özgül yakıt tüketimi $[\mathrm{kgY} / \mathrm{kWh}]$

BA : Buji ateşlemeli

C : Segman sızdırmazlık katsayısı [1/s]

$C_{p i} \quad$ : Sabit basınçta özgül $1 \mathrm{~S} 1[\mathrm{~kJ} / \mathrm{kg} / \mathrm{K}]$

D : Silindir çapı [mm]

EGR : Egzoz gazı resirkülasyonu

$F_{s} \quad$ : Stokiyometrik yakit/hava oranı [-]

$h_{g i}$ : Taşınımla 1sı transfer katsayısı $\left[\mathrm{W} / \mathrm{m}^{2} \mathrm{~K}\right]$

$h_{i} \quad:$ Entalpi $[\mathrm{kJ} / \mathrm{kg}]$

$h_{L} \quad$ : Gaz kaçaklarından kaynaklanan entalpi kaybı $[\mathrm{kJ} / \mathrm{kg}]$

$\mathrm{H} \quad$ : Strok uzunluğu [mm]

$H_{L} \quad$ : Entalpi kaybi [J]

$H_{u} \quad$ : Alt 1 sil değer $[\mathrm{kJ} / \mathrm{kg}]$

KMA : Krank mili açısı

KTB : Kenarda tek buji

$l_{b} \quad:$ Biyel kolu uzunluğu [mm]

$m \quad$ : Yakıtın toplam kütlesi $[\mathrm{kg}]$

$\dot{m}_{L} \quad$ : Kütle kayıpları $[\mathrm{kg} / \mathrm{s}]$

MBT : En yüksek momentin elde edildiği ateşleme zamanı [ $\left.{ }^{\circ} \mathrm{KMA}\right]$

MTB : Merkezde tek buji

n : Motor devri sayısı $[\mathrm{d} / \mathrm{d}]$

ÖYT : Özgül yakıt tüketimi

p : Basinç [bar]

$p_{0} \quad:$ Atmosfer basinc1 [bar]

$p_{m e}$ : Ortalama efektif basınç [bar]

$p_{m i}$ : Ortlama indike basınç [bar]

$p_{m, m}$ : Mekanik kayıplar ortalama basıncı [bar]

$Q_{L} \quad$ : Isı kaybi [J]

$r_{L} \quad$ : Krank dairesi yarıçapının biyel kolunun uzunluğuna oranı

$R \quad$ : İdeal gaz sabiti $[\mathrm{kJ} / \mathrm{kg} / \mathrm{K}]$

SÇB : Simetrik çift buji

$T \quad:$ Sicaklık [K]

$T_{0} \quad$ : Atmosfer sicaklığ $[\mathrm{K}]$

$u \quad:$ İç enerji $[\mathrm{kJ} / \mathrm{kg}]$

ÜÖN : Üst ölü nokta

$v \quad:$ Özgül hacim $\left[\mathrm{m}^{3} / \mathrm{kg}\right]$

$V \quad:$ Silindirin anlik hacmi $\left[\mathrm{m}^{3}\right]$

$V_{c} \quad:$ Ölü hacim $\left[\mathrm{m}^{3}\right]$

$V_{h} \quad$ : Strok hacmi $\left[\mathrm{m}^{3}\right]$

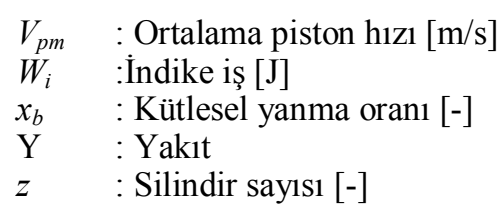

Yunan harfleri (GreekSymbols)

$\varepsilon_{s} \quad:$ Sikıştırma oranı $[-]$

$\eta_{e} \quad:$ Efektif verim [\%]

$\eta_{v} \quad:$ Hacimsel verim $[\%]$

$\theta \quad:$ Krank mili açısı $\left[{ }^{\circ}\right]$

$\theta_{s} \quad:$ Ateşleme açısı [ $\left.{ }^{\circ}\right]$

$\phi \quad$ : Ekivalans oranı [-]

$\omega \quad$ : Açısal hız [radyan/s]

Alt indisler (Subscripts)

$i \quad: u$ (yanmamış) ve $b$ (yanmış)

w : Silindir duvar1

\section{TEŞEKKÜR (ACKNOWLEDGEMENT)}

Bu çalışma, Karadeniz Teknik Üniversitesi Bilimsel Araştırma Projeleri Koordinasyon Birimi (BAP) tarafindan desteklenmiştir.

\section{KAYNAKLAR (REFERENCES)}

1. Dale, J.D., Checkel, M.D. ve Smy, P.R.,"Application of High Energy Ignition Systems to Engines", Progress in Energy and Combustion Science, Cilt 23, No 5-6, 379-398, 1997.

2. Hilditch, J., Han, Z., ve Chea, T., "Unburned Hydrocarbon Emissions from Stratified Charge Direct Injection Engines”, SAE Technical Paper 2003-01-3099, 2003.

3. Cavina, N., Corti, E., Minelli, G., Moro, D. ve Solieri, L., "Knock Indexes Normalization Methodologies", SAE Technical Paper 2006-012998, 2006.

4. Song, J., Sunwoo, M., “An Experimental Study on Engine Performance with High Ignition Energy", Proceedings of the Institution of Mechanical Engineers, Part D: Journal of Automobile Engineering, Cilt 216, 505-512, 2002.

5. Eriksson, L., "Spark Advance for Optimal Efficiency", SAE Technical Paper 1999-010548, 1999.

6. Batmaz, İ., Şahin, F. ve Bilgen, H., " Tek Silindirli Buji İle Ateşlemeli Bir Motorda Ateşleme Avansının Bilgisayarla kontrolü”, Journal of the Faculty of Engineering and Architecture of Gazi University, Cilt 26, No 4, 861-868, 2011.

7. Gupta, H.N., "Fundamentals of Internal Combustion Engines", PHI Learning,New Delhi, 2011.

8. Kalghatgi, G., Nakata, K., ve Mogi, K., "Octane Appetite Studies in Direct Injection Spark Ignition (DISI) Engines", SAE Technical Paper 2005-01-0244, 2005. 
9. Vancoillie, J., Sileghem, L., ve Verhelst, S., "Development and Validation of a Knock Prediction Model for Methanol-Fuelled SI Engines", SAE Technical Paper 2013-01-1312, 2013.

10. Altın, İ., Buji Ateşlemeli Bir Motorda İkiz-Buji Kullanılmasının Yanma ve Motor Performans Karakteristikleri Üzerindeki Etkilerinin Teorik Olarak İncelenmesi, Doktora Tezi, Karadeniz Teknik Üniversitesi, Fen Bilimleri Enstitüsü, 2011.

11. Maloney, P.J., "Objective Determination of Minimum Engine Mapping Requirements for Optimal SI DIVCP Engine Calibration", SAE Technical Paper 2009-01-0246, 2009.

12. Dale, J.D. ve Oppenheim, A.K., "Enhanced Ignition for I. C. Engines with Premixed Gases", SAE Technical Paper 810146, 1981.

13. Altın, İ. ve Bilgin, A., "A Parametric Study on the Performance Parameters of a Twin-Spark SI Engine", Energy Conversion and Management, Cilt 50, No 8, 1902-1907, 2009.

14. Altın, İ., Sezer, İ. ve Bilgin, A., " Effects of the Stroke/Bore Ratio on the Performance Parameters of a Dual-Spark-Ignition (DSI) Engine", Energy and Fuels, Cilt 23, No 4, 1825-1831, 2009.

15. Migita, H., Amemiya, T., Yokoo, K. ve Iizuka, Y., "The New 1.3-Liter 2-Plug Engine for the 2002 Honda Fit", JSAE, Cilt 23, 507-511, 2002.

16. Bozza, F., Gimelli, A., Siano, D., Torella, E. ve Mastrangelo, G., "A Quasi-Dimensional ThreeZone Model for Perfomance and Combustion Noise Evaluation of a Twin-Spark High-EGR Engine", SAE Technical Paper 2004-01-0619, 2004.

17. Anderson, R.W., "The Effect of Ignition System Power on Fast Burn Engine Combustion", SAE Technical Paper 870549, 4537-4546, 1987.

18. Chandra, H., "A Critical Study of the Dual versus Single Plug Systems in S.I. Engines", SAE, No 940452, 93-102, 1994.

19. Nakamura, N., Baika, T. ve Shibata, Y., "Multipoint Spark Ignition for Lean Combustion", SAE Technical Paper 852092, 1985.

20. Kuroda, H., Nakajima, Y., Sugihara, K., Takagi, Y. ve Muranaka, S., "The Fast Burn with Heavy EGR, New Approach for Low NOx and Improved Fuel Economy", SAE Technical Paper 780006, 1978.

21. Yamamoto, H., Horita, S. ve Matsuoka, T., "Surrounding Combustion Process (SCP)- New Concept for Lean Burn Engine", SAE Technical Paper 920058, 1992.

22. Russ, S., Lavoie, G. ve Dai, W., "SI Engine Operation with Retarded Ignition: Part 1-Cyclic Variations", SAE Technical Paper 1999-013506, 1999.

23. Lavergne, R. ve Hallot, J., "Investigation of the Effect of Double Ignition on the Combustion Processes in a 2-valves Gasoline Engine Through
3D Simulation”, SAE Technical Paper 2003-010010, 2003.

24. Piccone, A., Lanati, P. ve Scapecchi, P., "Twin Spark Engine", SAE Technical Paper 894381, 1989.

25. Fiorenza, R., Formisano, G., Martorelli, M. ve Sbarbati, F., "Combustion/NVH Analysis for Development of a 2-Valve Double Spark Plug Engine", SAE Technical Paper 2005-01-0236, 2005.

26. Jatana, G.S., Himabindu, M., Thakur, H.S. ve Ravikrishna, R.V., "Strategies for High Efficiency and Stability in Biogas-Fuelled Small Engines", Experimental Thermal and Fluid Science, Cilt 54, 189-195, 2014.

27. Dubey, A., Pareta, A. ve Sharma, P., "Study of Multiple Spark Ignition Engines with Single Spark Ignition Engines on the Basis of Engine Efficiency and Emission Characteristics Size", International Journal of Current Engineering and Technology (Special Issue-3), 14-17, 2014.

28. Gürbüz, H., Buran, D. ve Akçay, İ.H., "Buji Ateşlemeli Hidrojen Motorunda Karışım Oranı ve Ateşleme Avansının Motor Performansina ve Çevrimler Arası Farka Etkisinin Deneysel Araştırılması", Journal of the Faculty of Engineering and Architecture of Gazi University, Cilt 26, No 1, 105-114, 2011.

29. Abd Alla, G.H.A.,"Computer Simulation of a Four Stroke Spark Ignition Engine", Energy Conversion and Management, Cilt 43, No 8, 1043-1061, 2002.

30. Ferguson, C.R., Intenal Combustion Engines Applied Thermosciences, Jhon Wiley \& Sons Inc., Singapore, 1986.

31. Bilgin, A., "Geometric Features of the Flame Propagation Process for an SI Engine Having Dual-Ignition System", International Journal of Energy Research, Cilt 26, No 11, 987-1000, 2002.

32. Bayraktar, H. ve Durgun, O., " Mathematical Modeling of Spark-Ignition Engine cycles", Energy Sources, Cilt 25, No 7, 651-666, 2003.

33. Poulos, S.G. ve Heywood, J.B., " The Effect of Chamber Geometry on Spark-Ignition Engine Combustion", SAE, No 830334, 1106-1129, 1983.

34. Li, X., Mikulec, T., Dai, W. ve Qian, X., “ A Generic Methodology for Chamber Flame Geometry Modeling”, SAE, No 2000-01-2797, 1$17,2000$.

35. Altın, $\dot{\mathrm{I}}$. ve Bilgin, A., "Buji Ateşlemeli Motorlarda Alev Cephesinin Geometrik Özelliklerinin Katı Model Programı Kullanılarak Belirlenmesi", $10 . \quad$ Uluslararası Yanma Sempozyumu, Sakarya Üniversitesi, Sakarya, 296-300, 9-10 Ekim 2008.

36. Durgun, O., İçten Yanmalı Motorlar Ders Notları (basılmamış), KTÜ, Trabzon, 2009.

37. Heywood, J.B., Internal Combustion Engines Fundamentals, McGraw-Hill Book Co., Singapore., 1988. 